\title{
Coenosia wulpi (Pont) (Diptera, Muscidae, Coenosiinae): redescription of male, description of female and terminalia
}

\author{
Márcia S. Couri
}

Museu Nacional, Universidade Federal do Rio de Janeiro. Quinta da Boa Vista, 20940-040 Rio de Janeiro, Rio de Janeiro, Brasil. Research Fellow CNPq. E-mail: mcouri@attglobal.net

\begin{abstract}
Coenosia wulpi Pont, 1972 (Diptera, Muscidae, Coenosiinae) is the only Coenosia Meigen, 1826 species recorded from Mexico. It is known only from the holotype male deposited at "The Natural History Museum" collection (London, United Kingdom). A series of five males and seven females was found at California Academy of Sciences collection (San Francisco, California), which enabled the redescription of the male, and the description of the female and the male and female terminalia, for the first time.
\end{abstract}

KEY WORDS. Morphology; taxonomy.

RESUMO. Coenosia wulpi (Pont) (Diptera, Muscidae, Coenosiinae): redescrição do macho, descrição da fêmea e das terminálias. Coenosia wulpi Pont, 1972 (Diptera, Muscidae, Coenosiinae) é a única espécie de Coenosia Meigen, 1826 registrada para o México. Ela é conhecida apenas do holótipo macho depositado na coleção do "The Natural History Museum" (Londres, Reino Unido). Uma série de cinco machos e sete fêmeas foi encontrada na coleção do California Academy of Sciences (São Francisco, Califórnia), o que permitiu a redescrição do macho e a descrição da fêmea e das terminálias masculina e feminina, pela primeira vez.

PALAVRAS-CHAVE. Morfologia; taxonomia.

Coenosia wulpi Pont, 1972 (Diptera, Muscidae, Coenosiinae) was originally described by Wulp (1897) in Schoenomyza pulicaria, based in one male collected in Mexico (in Omilteme, Guerrero) at 8,000 feet high, which is deposited at "The Natural History Museum" (London, United Kingdom). Since the original description no more specimens were identified or found in collections and all further references to this species were in taxonomic lists or catalogues (Stein 1919, Huckett 1934, SÈGuY 1937, Pont 1972 , Couri \& Carvalho 2002, Carvalho et al. 2005).

PonT (1972) transferred the species to Coenosia Meigen, 1826 and proposed the new name - Coenosia wulpi - for Schoenomyza pulicaria as it was a junior secondary homonym of C. pulicaria (Zetterstedt, 1845)

This paper aims to redescribe the male and describe the female and the male and female terminalia, for the first time.

\section{MATERIAL AND METHODS}

The material studied in this paper was collected by Swan in altitudes between 12000 and 13500 feet high. The material belongs to California Academy of Sciences collection (CAS, San Francisco, California) and will be deposited there and in Museu Nacional, Rio de Janeiro (MNRJ) collection, as indicated in the Material Examined.

The dissected terminalia were clarified in a solution of
$10 \%$ potassium hydroxide for 24 hours. They were then dissected in glycerol, drawn, stored in a microtube with glycerol, and attached to the pin bearing the specimen.

\section{RESULTS AND DISCUSSION \\ Coenosia wulpi Pont, 1972}

Figs 1-7

Coenosia wulpi Pont, 1972: 44 (nom. nov. for pulicaria Wulp); Carvalho et al., 1993: 117 (catalogue); Couri \& Carvalho, 2002: 217 (listed); Carvalho et al., 2005: 186 (catalogue).

Coenosia pulicaria Wulp, 1897: 346, pl. 8, fig. 18 (Schoenomyza).

[Junior secondary homonym of pulicaria Zetterstedt, 1845.]

Schoenomyza pulicaria; Stein, 1919: 156 (cat.); Séguy, 1937: 193 (cat.).

Hoplogaster pulicaria; Huckett, 1934: 106 (listed).

Type. Male holotype, deposited at "The Natural History Museum, BMNH (London, United Kingdon) [not examined]. Type-locality: Mexico, Guerrero, Omilteme. 8000 feet.

Diagnosis. The species can be characterized by its small size; by the very small calypters, the inferior one shorter than the superior and by the shape of sternite 5 .

Male. Body length: $2.5 \mathrm{~mm}$; wing: $2.8 \mathrm{~mm}$

General coloration. Ground color dark brown with grey 

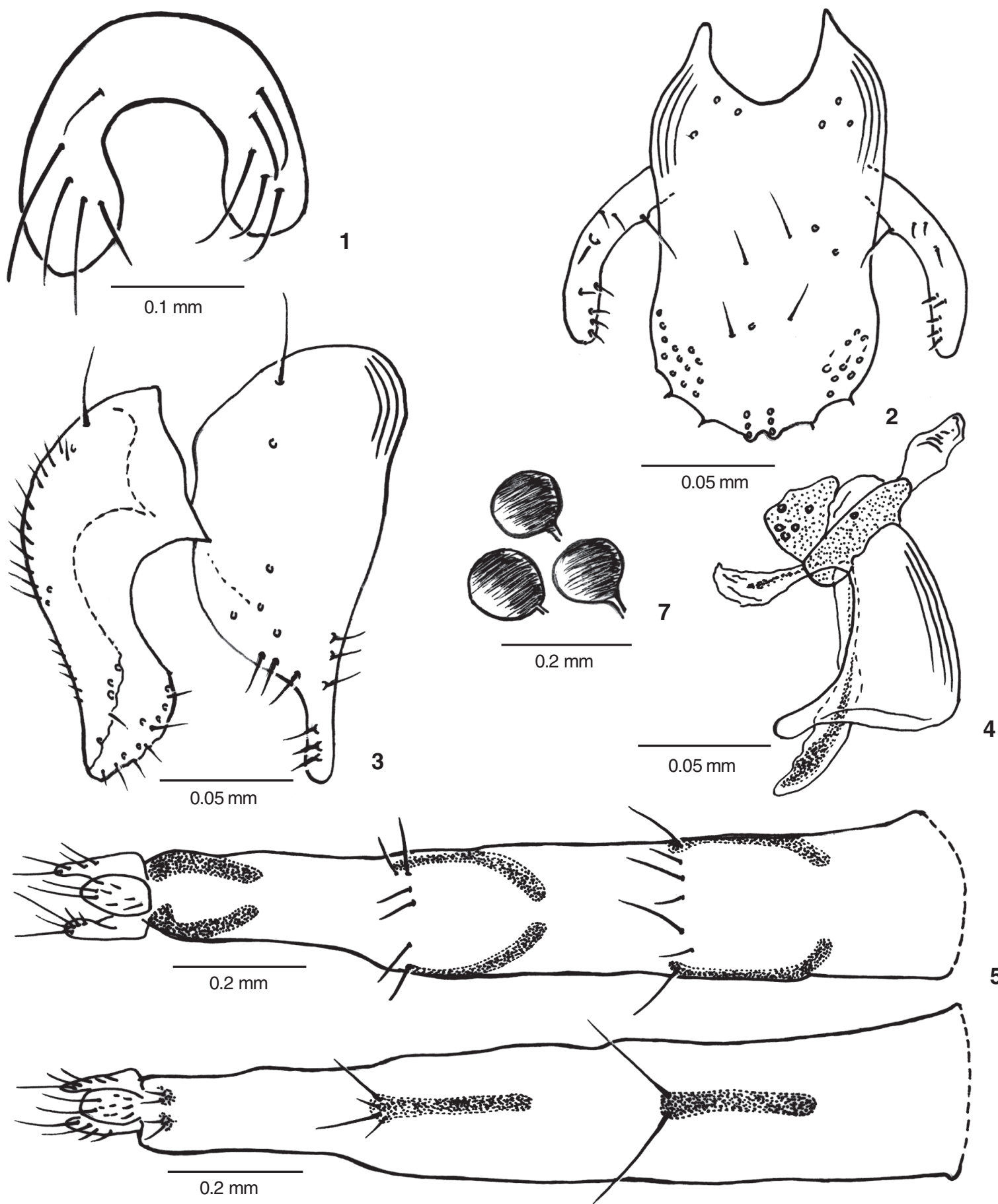

Figs 1-7 Coenosia wulpi. (1-4) Male: (1) sternite 5; (2) cercal plate and surstyli, dorsal view; (3) cercal plate and surstylus, lateral view; (4) aedeagus, lateral view; (5-7) female: (5) ovipositor, dorsal view; (6) ovipositor, ventral view; (7) spermathecae.

pollinosity; frons dark brown with few grey pollinosity; frontoorbital plate and gena brown, silver pollinose. Antenna, arista and palpus dark brown. Dorsum of mesonotum with four brown vittae. Calypters whitish and halter yellow. Wing clear. All legs 
dark brown with grey pollinosity, extreme apex of fore femur and base of fore tibia yellow. Abdominal tergites 1+2-4 with three pairs of quadrangular faint brown spots.

Head. Male dichoptic; distance of eyes at vertex about one third of head width. Frontal row with four pairs of setae, the upper one backwards directed. Inner and outer vertical setae developed. Ocelar setae long. Antenna long, inserted at middle level of eyes; with flagellomere measuring about 2.8 times the pedicel length. Arista with very short cilia. Palpus filiform. Cheek broad. Vibrissa long, with one medium supravibrissal and three medium sub-vibrissal.

Thorax. Dorsocentrals 1:3; acrostichals short, in one series; 1 postpronotal; 1 presutural; 1 intralar; 2 supralars; 2 postsupralars. Notopleuron with two setae, similar in size. Scutellum with one medium pair of basal setae and one long apical about twice the length of the basal. Anepisternum with two long setae, each one preceeded by a fine one. Katepisternals 1:1:1, forming an equilateral triangle. Katepimeron bare. Both calypters short, the inferior one totally covered by the superior one. Wing veins $R_{4+5}$ and $M_{1+2}$ parallel at apex. Legs with fore femur with four dorsal setae on basal half and six ventral sparse setae on its all extension; fore tibia with no setae on middle; claws and pulvilli very short; mid femur with three sparse ventral setae on basal half; posterior surface with one preapical; mid tibia with one median anterodorsal and one median posterior seta; one strong apical on anteroventral, ventral and posteroventral surfaces; hind femur with five anterior sparse setae and four preapical setae on ventral, anterodorsal, dorsal and posteroventral surfaces; hind tibia with one sub-median anteroventral, one median anterodorsal, a long pre-apical dorsal and a strong apical ventral setae.

Abdomen. Elliptical; tergite 5 with one pair of basal lateral setae and five long and fine apical setae. Sternite 5 " $U$ " shaped with few setae on sides (Fig. 1).

Terminalia. Cercal plate rectangular, with no anterior incision and with few setae on disc (Figs 2-3). Hypandrium tubular and long (Fig. 4).

Female. Length $3.5 \mathrm{~mm}$, wing: $3.8 \mathrm{~mm}$

Similar to male, differing as follows: visibly larger in size than male; gena broader; hind femur with a row of sparse setae on anteroventral and anterodorsal surfaces, and no setae on anterior surface.

Ovipositor. Long, with thin tergites and sternites, as in figures 5-6. Three spermathecae round, more or less of same size (Fig. 7).

Material examined. Mexico: S. E. Citaltepetl, el. [elevation] 13500, 13.VII.1964, LW Swan; 4 males (3 CAS; 1 MNRJ) and 3 females (2 CAS, 1 MNRJ); el. [elevation] 13500, 12 July 1964, 2 males (CAS) and 2 females (CAS); el. [elevation] 12000, 14.VII.1964, 1 female (CAS).

Discussion. In the original description the species was placed in the genus Schoenomyza Haliday, 1833 mainly due to the small inferior calypter, although it does not fit others

Schoenomyza characters. It occurs in high altitudes and this is the only Coenosia species recorded from Mexico.

\section{ACKNOWLEDGMENTS}

I am grateful to all staff at the Department of Entomology of the California Academy of Sciences (San Francisco, California), especially Norman Penny for all the support during a post-doctoral project developed in that institution in 2005. I also acknowledge Coordenação de Aperfeiçoamento de Pessoal de Nível Superior (Process 3123-04-9), an agency of the Brazilian Government fostering scientific and technological development, for the post-doctoral grant and to Conselho Nacional de Desenvolvimento Científico e Tecnológico for the research grant (Process 300370/2004-0).

\section{REFERENCES}

Carvalho, C.J.B. de; M.S. Couri, A. C. Pont; D. Pamplona \& S. M. Lopes. 1993. Part II. Muscidae, p. II.1-II.174. In: C.J.B. DE CARVALHO (Ed.). A catalogue of the Fanniidae and Muscidae (Diptera) of the Neotropical region. São Paulo, Sociedade Brasileira de Entomologia.

Carvalho, C.J.B. DE; M.S. Couri; A.C. Pont; D. Pamplona \& S.M. LOPEs. 2005. A Catalogue of the Muscidae (Diptera) of the Neotropical Region. Zootaxa 860: 1-282.

Couri, M.S. \& C.J.B. De Carvalho. 2002. Part II. Apical Groups, p. 133-287. In: C.J.B. DE CARvalho (Ed.). Muscidae (Diptera) of the Neotropical Region: taxonomy. Curitiba, Editora da Universidade Federal do Paraná, 287p.

HucketT, H.C. 1934. A revision of the North American species belonging to the genus Coenosia Meigen and related genera (Diptera: Muscidae). Part I. The subgenera Neodexiopsis, Coenosia, Hoplogaster and related genera Allognota, Bithoracochaeta and Schoenomyza. Transactions of the American Entomological Society 60: 57-119.

PonT, A.C. 1972. A Catalogue of the Diptera of the Americas South of the United States. 97. Family Muscidae. São Paulo, Museu de Zoologia, Universidade de São Paulo, 111p.

SÉGuy, E. 1937. Diptera Fam. Muscidae. In: P. Wytsman (Ed.). Genera Insectorum. 205. Brussels, Desmet-Verteneuil, 604p.

Stern, P. 1919. Die Anthomyidengattungen der Welt, analytisch bearbeitet, nebst einem kritisch-systematischen Verzeichnis aller aussereuropäischen Arten. Archiv für Naturgeschichte 83A 1: 85-178.

Wulp, F. M. van DER. 1897. Group Anthomyiinae. [Concl.], p. 345-360. In: F.D. Godman \& O. SALVIN (Eds). Biologia Centrali-Americana. London, Taylor \& Francis Zoologia-InsectaDiptera 2, Part 137.

Received in 01.XI.2006; accepted in 02.V.2007. 